\title{
COSAS Y PALABRAS DEL NOROESTE IBÉRICO
}

\section{UN SISTEMA DE GULTIVO ARCAICO: LA QUEMA DEL MONTE}

En las zonas montañosas del Noroeste de la Península Ibérica se ha conservado una forma de cultivo que seguramente se remonta a tiempos muy antiguos y que en ellas ha mantenido hasta la actualidad su carácter tradicional. Trátase del aprovechamiento de los montes, que se practica en dos formas distintas: unas veces se trata de crear buenos pastos, y otras se roturan periódicamente las tierras para sembrar centeno. En ambos casos se hacen rozas y quemas en los sitios que se creen más a propósito, y este sistema está vinculado con ciertos usos de la comunidad, que dan a la vida económica del Noroeste un carácter tan arcaico como particular. Estas prácticas - hace notar un observador gallego- proporcionan a la aldea dos ventajas: primera, que las cosechas se producen con poquísimo trabajo, pues apenas si se remueven las cenizas que dejó en la tierra el monte quemado para sembrar el centeno; segunda, que las tierras quemadas dan después mejores pastos, aprovechables para el ganado vacu no en las épocas en que los prados y lamas apenas tienen hierbas (TENorio, La aldea gallega, Cádiz, I 9 I 4, pág. 2 I). Tales costumbres se han conservado hasta hoy en Asturias, en Galicia, en tierras leonesas, así como en el Norte de Portugal, con todo su sabor primitivo. También encontramos huellas esporádicas en otras regiones.

En el presente artículo no haremos un estudio exhaustivo sobre una materia tan compleja ${ }^{\mathrm{I}}$, sino más bien quisiéramos presentar algunos datos

${ }^{1} \mathrm{He}$ aquí unas cuantas referencias bibliográficas: N. Tenorio, La aldea gallega, págs. 20-2 I; V. Risco, Terra de Melide, Santiago, I933, págs. 364 ; W. EвeLING, Die landwirtschaftlichen Geräte im Osten der Provinz Lugo, en VKR, V, I932, págs. I06-107, I 27 y I3I; V. TABorda, Alto Trás-os-Montes, Coimbra, I932, pág. i i6; A. De Amorim GiRÃo, en Biblos, XII, I936, pág. 52 (con una fotografía de la queimada en la Serra de Caramulo; tal vez se refiera el mismo insigne geógrafo a esta forma de cultivo también en su Geografia de Portugal, obra que por el momento no me es accesible); C. Alb. Marques, en Biblos, XII, I936, págs. 20I-202 (Bacia do Coa); A. Girẽo, Bacia do Vouga, Coimbra, I922, págs. I37i38; Silva Picão, Atravez dos campos, Elvas, I903, vol. I, págs. 41-42; vol. II, págs. 54 y 55. Remito finalmente a Hochpyrenäen, C, II, págs. 22-27, donde el lector encontrará una descripción del mismo sistema de cultivo en los Pirineos, con datos comparativos. 
recogidos directamente o de vocabularios, con el fin de exponer la importancia que tiene el tema, tanto desde el punto de vista lingüístico como para la etnografía peninsular, que todavía no se ha ocupado de un asunto tan atractivo.

La primera acción consiste en s e g a r e $1 \mathrm{roz}$, es decir, en limpiar el terreno poblado de árgoma, brezo y otras plantas propias del monte bajo:

rozar, en Asturias (Braulio Vigón; Acevedo, etc.), Galicia (Valladares; Tenorio, pág. 20; Risco, pág. 364), León (Álvarez, BabiaLaciana: ruzar) y en otras provincias del Oeste (Es PINosa, Arcaísmos dialectales, pág. 28: rozal), así como en Portugal (roçar a terra, roçar mato, TAvares da SILva, Esbốco dum vocabulário agricola regional, pág. 393 ; roçar Alto Minho, $R L u, \mathrm{XXV}$, I 923-24, pág. 203; Alentejo, BCLL, $\mathrm{XV}$, pág. I 40 , etc.). = cast. rozar, esrozar en la Rioja (RDTP, IV, I948, pág. 284), REW, 7453 * r u p t i a r e. Es inadmisible la etimología propuesta en algunos estudios dialectales recientes: * r o d i a r e.

Cabe añadir las siguientes formas deverbales:

roza 'sitio poblado de árgoma' Asturias (Llano RozA, Folklore asturiano; BRAUlio VIGóN), 'terreno inculto recientemente rozado' bable occidental (Acevedo); 'terreno cerrado, abundante en rozu'; rozada 'terreno limpio de rozu, que se acaba de rozar' Cabranes (Caneliada);

roza 'corta de tojos, arbustos y malezas' Galicia (Valladares; CuVEIRO PIÑOL);

rozada 'acción de desbrozar un trozo de monte para sembrarlo' Bierzo (GARGía REY) ; roçada 'a operação de roçar' Alto Minho ( $R L u$, XVIII, pág. I $48 ; \mathrm{XXV}$, I923-24, pág. 203);

roçado 'terreno em que se roçou o mato' (FIgUeIREDo);

roço 'mato roçado ou em estado de ser roçado' Alto Minho ( $R L u$, XXV, 1923-24, pág. 203);

roça 'mato roçado; acto de roçar' Alentejo (SIlva Picão, Atravez dos campos, I, pág. 4 I ; II, pág. 55).

Encontramos los mismos términos en el hispanoamericano (SAntaMARía : rozar; roza, rozadura) y brasileño (Pereira da Costa, Vocabulário pernambucano, págs. $635-636$, etc.).

rozadio 'terreno que por abundar en rozo, árgomas y zarzas, se puede rozar', prov. de Santander (GARGía Lomas, pág. 308; BBMP, II, I920, pág. I I 5 ).

El árgoma segada se utiliza en muchas partes para hacer las camas del ganado y como combustible en los hornos. Se emplea en este sentido especial el masculino rozu en la prov. de Santander y en Asturias (GARcí́ Lomas; BBMP, II, i920, pág. 258; Braulio Vigón; AGevedo).

Mezclados con los excrementos del ganado, las hojas secas y los arbustos dan también un abono vegetal excelente. Extiéndense por esto en invierno en las calles y caminos próximos a los pueblos, con el fin de 
hacerlos fermentar. Presentan un espectáculo curiosísimo, durante larga temporada, los pueblos asturianos, gallegos, leoneses y trasmontanos, con sus caminos cubiertos de un tapiz de abono naciente.

El instrumento usado para la siega del rozo es una especie de $\mathrm{g} \mathrm{u} \mathrm{a}$ $\mathrm{d}$ a $\tilde{\mathrm{n}} \mathrm{a}$, de hoja corta, pero más gruesa que la de la guadaña ordinaria: rozón Asturias (Rato y Hévia; Braulio Vigón; Acevedo), rozón, al lado de gadaño, en el este de la prov. de Lugo (Ebeling, $V K R, \mathrm{~V}$, I932, pág. I 23 , con dibujo ı $6 a$ ).

Se utiliza también una especie de $\mathrm{pod}$ a d e r a, con astil de madera, para rozar zarzas y otros arbustos:

rozadera Bierzo (GARcía REY).

fouz, fouz de rozar, en el suroeste de Asturias; fouce Galicia (VAllaDARes; Cuveiro PiÑol), fouciño para rozar toxos, foucin, etc., en el este de la prov. de Lugo (VKR, V, I932, págs. I20-I2I), fouce ruzadeira, fouce rozadoira, rozadeira, ruzadeira Sanabria (Gegenstandskultur Sanabrias, pág. 23 I), fouce roçadoira 'de cortar silvas', etc. Entre-Douroe-Minho (Fort, I, pág. 637; Leite de Vasconcelos, Opúsculos, vol. II, pág. 49I), roçadoira 'uma podoa com o cabo comprido' Coa (Biblos, XII, I936, pág. 20I ), ruçadoira Serra da Estrêla (VKR, IV, I93I, pág. I59, con dibujo 22), roçadoura Alentejo (BCLL, XV, pág. I 4o), etc. calagouzo, calabouzo, etc., en sanabrés, etc. (Gegenstandskultur $\mathrm{Sa}$ nabrias, págs. 23I-232), vocablos que A. Castro ( $R P E, V$, I9I8, pág. 3I) se inclina a derivar de bouza (véase infra, págs. 243-244).

Para recoger la roza del monte, se utiliza una h or quilla, toda de madera y provista generalmente de tres ganchos, parecida a las formas primitivas de horquilla descritas en Hochpyrenäen, G, II, págs. $405 \mathrm{y}$ sigs. :

gayón en el bable central (CANellada: la cantidad de rozu que se coge de una vez con el gayón), gallo, gallada en la prov. de Lugo ( $V K R$, $\mathrm{V}$, I932, pág. I 55); galla, galleiro prov. de Orense, galha, galheira Minho (Gegenstandskultur Sanabrias, pág. 239; Hochpyrenäen, C, II, pág. 407); galha, gayo, etc., originariamente = 'gajo, rama de árbol' (REW, $3629 a)$.

furcada Asturias, Galicia, etc.

Para arrancar la hierba, los tojos, el brezo, o cualquier otra especie de revestimiento vegetal, hay que $\mathrm{c}$ a va $\mathrm{r}$ e l t e $\mathrm{r}$ reno (cavar monte). Sirve a este fin una a $\mathrm{z}$ a d a de forma especial, llamada en el suroeste de Asturias rozón Besullo; xada ( $x=$ palatal fricativa) Bruelles, Trones, eixada Bao, como también en el este de la prov. de Lugo, aixada, eixada (VKR, V, I932, págs. I27-128, fig. I $8 a$ ), enxada, en Trás-osMontes ( $R L u, \mathrm{XXXV}$, I937, pág. 280, para cortar mato), Barceh̉os (Gomes Pereira, Barcellos, pág. 245) y probablemente también en otros dialectos occidentales. (Cf., para las variantes fonéticas de 'azada', 
el artículo de Aurelia Muelas, Sinonimia de "azada", RDTP, II, I 946, págs. 278-285).

Caracterizan muy bien las operaciones de que acabamos de hablar y el paisaje en el cual se van desarrollando, los t o p ó $\mathrm{n}$ i m o s siguientes: las tierras del rozu, las tierras de rozas, el rozu, los rozus, los rozus del fluexu ( $x=$ palatal fricativa), el ruzón en Babia y Laciana (Álvarez, págs. I 7-I 8, I 95, I96) y los nombres de montes que encontré en la parte colindante de Asturias y Galicia: el rozo Puerto de Leitariegos, rozua Bao, as rozas Folgoso, as rozadas Folgoso. Son frecuentísimos también en Galicia: Rozas, Rozasvedras, Rozada, Rozadela, Rozabales, etc. (Nomenclátor de las ciudades, villas, lugares, aldeas de España: Provincia de Lugo) y Portugal: Rozas, 946; Roza, I220 (CoRTesão, Onomástico medieval português); roça (Gomes Pereira, Barcellos, págs. 347, 375). Valdría la pena agotar los nomenclatores geográficos de España y Portugal (que actualmente no están a mi alcance) para dar una idea completa de la difusión geográfica de términos de esta categoría.

En la zona montañosa del Norte, los arbustos y las raíces se llevan a casa, donde se utilizan como combustible del horno o en el llar de la casa. Por lo general, sin embargo, la mata, después de rozada, se junta en montoncitos para dejarla secar algún tiempo. Una vez secos, se queman los montones, y su ceniza sirve para abono del suelo. En las sierras del Noroeste, esta costumbre arcaica toma un carácter verdaderamente grandioso. A fines de verano o a principios de otoño se queman también los residuos de la mata en el propio local donde fué antes rozada, con el objeto de utilizar como abono la ceniza de la tierra quemada. "Nas terras de montaña —relata un observador gallego- vé-se ô lonxe pol-o vrau, arder o monte en moitos lados, dando de día un basto fume azul que vai empardecendo conforme sube, e véndose de noite as luces e o resprandor das flamas baixas, coma s'estiveran alcendendo braseiros eiquí e acolá. Ollando ô lonxe, as mais das veces é o fume o úneco que se move na calma azul da larganzía” (V. Risco, Terra de Melide, pág. $364)$.

Es lo que llaman la queimada, sobrevivencia de un antiquísimo modo de cultivar la tierra, que en el Noroeste de la Península se ha conservado en su forma más original, o fazer a bouça (boucha) en la Bacia do Coa (Biblos, XII, I936, pág. 202), hacer una bouza en el Bierzo (García REY). Véase, sobre este vocablo, infra, págs. 243-244.

Donde no hay mata suficiente para arder a por pé $=$ 'quemar de raíz', hacen monton citos de te rrones secos o de arbustos y yerbas cubiertos con tierra que, encendidos después, sirven igualmente para abonar las matas y prepararlas para el cultivo. He aquí las denominaciones que dan a tales montones:

I. borrón, en grandes sectores de Asturias (RAto y HÉvia; Llano Roza, Esfoyaza de cantares asturianos, Oviedo, I924, pág. I9o: "Tien más 
trabayu con ella / que cabar y fer borrones", en una canción popular; Acevedo), incluso en el Suroeste, donde encontré borrones Bruelles, borrones de rabina Cangas, burrones Pambley; véase también RDTP, III, 1947, pág. I O2 ; borronada 'conjunto de varios borrones', inf. aborron ar, borronear 'hacer borrones' (RATO y Hévia).

barroeira, barrueira en la zona astur-gallega (ACEvedo); barroeira Galicia (Valladares), burrueira en el este de la prov. de Lugo ( $V K R$, V, I932, págs. I05, I3I); inf. aborruar, abarruar (ACEVEDo).

borróa Galicia (Dicc. Acad. Gall.; Carré Alvarellos);

borralleira Galicia (Dicc. Acad. Gall; Valladares; Carré AlvaRELLOS); inf. aborrallar 'quemar un monte para sembrar después', 'abonar los prados con ceniza' (CARré Alvarellos), borrallada, emborrallada 'conjunto de borralleiras' (Dicc. Acad. Gall.); port. borralheira 'moreia' (TAvares da Silva, Esbôço dum vocabulário agrícola regional, pág. 95, sin indicación geográfica).

borrea Galicia (RIsco, Melide, pág. $364 ;$ RDTP, III, I947, pág. I02: Lugo); Dicc. Acad. Gall.: borréa, borreu, aborréa, borrela.

Encontramos derivados de la raíz borr- también con la acepción de:

'polvo', 'ceniza', etc.: gall. borralla 'polvo menudo' (VAlladares), port. borralha 'poeira da estrada' (TAVARES DA Silva, pág. 94); borrallo y sus variantes fonéticas 'ceniza caliente, rescoldo' Galicia, Trás-os-Montes, Bierzo, Cabrera, Sanabria (Gegenstandskultur Sanabrias, pág. I 37 , nota 4), Canarias (Lugo, págs. 70-7 I) ; extr. borraho (VKR, II, I929, pág. 86); Dicc. Acad. borrajo; gall. borrallo 'hoguera al aire libre para asar patatas' (RDTP, III, I947, pág. I02);

'el sitio donde se recoge la ceniza, generalmente detrás del mismo hogar': gall. borralleira (VALladares), borrayeira Cabrera (CASAdo Lobato, pág. I04), borralheira Minho, buralleira Sanabria (Gegenstandskultur Sanabrias, pág. 137, con -r-), etc.

Según García de Diego ( $R F E, \mathrm{X}, \mathrm{I} 923$, pág. I 26 ), aparece también gall. borro 'hollín', acepción que no he encontrado en los diccionarios, aunque sí he hallado borro, borrallo 'poso, sedimento y heces de alguna cosa más o menos líquida' (VAlladares), = esp., port. borra 'depósito ou impurezas de um líquido', berc. borra 'hez que se forma en las cubas' (GARcía Rey, pág. 55), 'residuos de exprimir la manzana al fabricar la sidra' en el bable central (GANelladA, pág. I 24), borriço 'borras, depósitos ou impurezas de um líquido’ Alto Minho ( $R L u$, XIX, Igi6, pág. I96), etc.

Relaciónanse semánticamente con los vocablos citados los siguientes: gall. borralla 'llovizna casi imperceptible; niebla que moja' (Dicc. Acad. Gall., pág. 335; la grafía boralla, con - $r$-, es evidentemente un error de imprenta); gall. borralleira 'niebla cuando anda baja y densa' (VALLADARES), astur. barruceiro 'se dice del día en que llovizna' (Acevedo), inf. barruzar, forma que encontramos también en Galicia = 'lloviznar, caer rocío'; corresponden a estos términos también el astur. borrina 'nie- 
bla densa y húmeda' (Rato y HÉvia), borrin, borrina 'niebla', inf. emborrináse en el bable central (CANELLADA), port. borraceira 'nevoeiro espêsso', borraceiro 'chuvisco', borriceira 'chuva miuda', borriceiro 'diz-se do tempo levemente chuvoso, borraceiro', borraçar, borriçar 'chuviscar', borriço 'chuvisco' (RLu, XIX, I916, pág. I96), borrifo 'pequenas gotas de chuva', borrifar 'molhar com borrifos', etc. (Figueiredo; Leite de Vasconcelos, Etnografia, vol. II, pág. 43; M. L. Wagner, ZRPh, LXIII, r943, pág. 344); cat. borrim 'lluvia menuda, de gotas menudas' (Dicc. Alcover). Sin entrar en una discusión de la repartición geográfica de borrasca, borrasquear y de las formas catalanas correspondientes, remitimos a $F E W, \mathrm{I}, 638 b$ y M. StefFen, Die Ausdrücke für Regen und Schnee im Französischen, Rätoromanischen und Italienischen, tesis doctoral de Zürich, 1935, pág. I I2, donde el lector hallará variantes de otras lenguas romances.

Encontramos por fin, fuera del Noroeste, borrajo 'hojarasca de los pinos' (Dicc. Acad.), borrajo, burrajo 'paja de garrobas; la paja u hojato que se destinan para la lumbre', 'la lumbre que se recoge a un lado del horno', borrajada, borrajera 'montón, hacinamiento de borrajos', en la provincia de Salamanca (Lamano), según Lamano, también borraja 'paja, hojato', borrajera 'hojarasca' en Aragón; borra 'paja inútil que queda al sacudir el centeno' en la Rioja ( $R D T P$, IV, 1948, pág. 275); arag. borrufalla 'hojarasca, fruslería, cosa de poca sustancia' (Borao), correspondiente a cat. borrufalla (relacionado por el Dice. Alcover con barruf-, etc.).

Obstinándose en el sentido de 'quemar montones' y 'ceniza o rescoldo', que en efecto aparece en numerosos derivados de borr-, el Sr. García de Diego propone una base etimológica b u r a r e, vocablo que se habría cruzado con * torrare de sentido parecido, burare, *bura t u 1 u m, * b u r a c u l u m (borrajo, etc.), RFE, IX, r922, págs. 125I 26. Se adhiere a la opinión del maestro la Srta. Casado Lobato en su tesis sobre la Alta Cabrera, pág. 6r. Lo que desorienta, sin embargo, es que en ninguna parte se encuentra el verbo borrar o burrar en el sentido de 'quemar', vocablo que, según la opinión de García de Diego, habría dado origen a una familia tan numerosa de sustantivos (los verbos arriba citados son, sin duda, formas denominales). Es evidente además que las

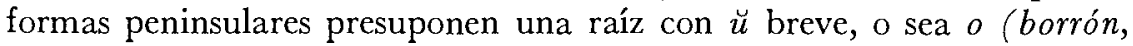
borroa, borrea, etc.), mientras que el verbo b u ra re presupone una $\bar{u}$ larga, o sea $u$. Contradicen la etimología propuesta, por fin, significaciones como borrajo 'hojarasca, paja de garrobas', borrufalla 'hojarasca', etc., palabras que no será lícito separar de los vocablos antes citados, y significaciones como borralla $=$ 'polvo', gall. borralla, etc. 'llovizna', port. borraceira, etc. 'nevoeiro', que en el estudio de García de Diego quedan sin mencionar (si no es que se admite un cambio semántico de 'ceniza' > 'polvo', 'llovizna', etc.). En vista de tantas dificultades y considerando además la vitalidad de borr- en otras lenguas romances, 
vitalidad que al mismo tiempo implica numerosas afinidades respecto a la significación de las palabras, me inclino a creer que hay que renunciar a las formas hipotéticas propuestas hace años por nuestro distinguido amigo, y volver a la etimología bur r a, presentada en $R E W$, I 4 I I (aceptada también en cuanto a las formas gallegas por EBELING, $V K R$, $V$, I932, pág. I31 ) y que respecto al galo-romance ha encontrado una documentación asombrosa en $F E W, I, 637$. Como en la Península ibérica, aparecen también en los dialectos galo-romances los derivados de borr- en el sentido de 'Iluvia fina', 'niebla', 'polvo', 'leña menuda', 'montón de polvo, de broza', etc.

No nos atrevemos en este momento a resolver la delicada cuestión de si hay relaciones directas, vale decir, parentesco antiguo entre los significados de ambos países, o (lo que será más probable en la mayoría de los casos) evolución independiente. Lo cierto es que la base borr-es común a la Iberorromania y a la Galorromania, y también en cuanto a las tendencias de la evolución semántica hay conformidad.

Opino que para explicar los significados que han motivado estas discusiones (astur. borrón = 'montón de broza'), hay que presuponer borren el sentido de 'broza', sentido que se ha conservado hasta hoy en sus derivados, y que tanta analogía tiene con borr- 'hojarasca'. En cuanto a los significados 'ceniza' y 'polvo' pueden ser derivados semánticos de aquéllos, si no se admite una rama propia independiente que reúna 'ceniza'-'polvo'-'lluvia fina', etc., dentro de la familia tan numerosa de los descendientes de borr-.

2. murrea, murrada Galicia (VAlladares, Cuveiro Piñol), amurrada Galicia (Dicc. Acad. Gall.), inf. amurrar 'quemar terrones secos y amontonados' (Valladares). Encierran estos vocablos un elemento nuevo, cuyo origen no es fácil de explicar. Según García de Diego (RFE, IX, 1922, pág. 126), se han fundido en estas palabras la forma y la significación de burare con las de otros vocablos, como morena 'montón de mieses y piedras', gall. morea (véase núm. 3). Pero existe también en la zona inmediata de Portugal murra, con diferentes matices: 'Num campo com cereal, as partes mais altas e viçosas, aonde em geral esteve a pilha do estrume, ou a terra é mais fertil . . chaman-se murras' ( $R L u$, XXII, I 9 I9, pág. 34); 'porção de mato que se corta, formando pequenas clareiras', Paredes-de-Coura ( $R L u$, XVI, pág. 255), 'mancha' (FIGUEIREDO).

3. moreia 'feixe de mato que no inverno se cobre com terra e que se queima no verão' Algarve ( $R L u$, VII, pág. 249; Tavares da Silva, Esbôço, pág. 319); también amoreia 'ilhota de mato no meio de um campo cultivado' Alentejo ( $R L u$, III, pág. 56), morea 'montículos de arbustos e ramagens de azinheiras e sobreiras amontoados nas clareiras da floresta; são depois queimados, servindo o calor e as cinzas de elemento fertilizador da terra, o que se conhece mais tarde pelos pequenos 
tufos, que, no meio da seara, se salientam pelo seu vigor' Alentejo ( $B C L L$, $\mathrm{XV}$, pág. I40; cf. supra la definición de murra). El vocablo moreia, morea, empleado en el sentido especial mencionado, parece pues limitarse a la parte sur de Portugal. Encuéntrase, sin embargo, también con el significado de 'meda', 'montón de gavillas de mies segada', 'leña apilada', etc. en otras partes de Portugal (cf. el artículo ricamente ilustrado de A. De Matros, Moreias, Douro-Litoral, IX, I944, págs. 3-I I ), en Galicia (morea 'montón de cualquier cosa', Valladares; 'montón de hierba', 'montón de paja' en la zona oriental), murena, mureña, murona 'leña apilada' Sanabria, morena, murena, usado en el mismo sentido en la Cabrera (Gegenstandskultur Sanabrias, pág. I23, con referencias a otras regiones), amorenar 'hacer las morenas en las tierras' Bierzo (GARCía REY), morenas 'montones de gavillas de mies segada' Maragatería y Santander (Garrote; García-Lomas).

Añadamos algunos términos de extensión más restringida:

4. pabeia, paveia 'cada um dos montículos de mato roçado' (FigueIreDo), 'molho de tojo formado de 4 coços', Monção ( $R L u, X X V, 1923^{-24}$, págs. I 83, 203), paveia de mato 'montinhos de mato cortados e postos a secar, próximos uns dos outros, para depois o terreno ser arroteado' Entre-Douro-e-Minho (LeITe de Vasconcelos, Opúsculos, vol. III, pág. 503). Aparece el mismo vocablo como designación de 'gavilla de mies': gall. pabea 'gavilla de mies antes de que se la ate en manojos' (Cuverro PIÑol), minh. pabeias 'pequenos feixes de palha', pabeal 'o conjunto de paveias de trigo ou centeio que os segadores vão deixando atrás de si' Arcos de Valdevez ( $R L u, \mathrm{XXV}, \mathbf{1 9 2 3 - 2 4}$, págs. I 83, 203); parece tener sentido semejante en la región de Semide (pabeias 'maranhos de milho juntados em braçados', $B d F$, III, I934-35, pág. 270) y en el Alentejo ("acumulam-se, na ceifa, os molhos de päo que formam as paveias", $R L u$, XXVI, I925-27, pág. 35); paveia 'molho de espigas de trigo' en las Azores (Silva Ribeiro). La etimología * p a b e l a $<$ p a b u l u m, propuesta en $B d F$, III, I934-35, pág. 278 , no satisface completamente.

5. panada 'pequeno montão de mato ou tojo; o tojo roçado e disposto em panadas no monte para secar' Alto Minho ( $R L u$, XXV, I923-24, pág. I 84); Figueiredo = 'paveia' Trás-os-Montes, Minho; panada de Ieña 'brazado de leña' Finisterre. Hay que relacionar estos vocablos tal vez con ant. port. apanar = apanhar 'recoger lo que está en el suelo', etc., gall. apanar 'asir con la mano', ast. pañar el herba 'recoger' (ACEVEDO).

6. caminheiras 'mêdas de lenha que se fazem nos terrenos limpos de mato, para serem queimadas antes da sementeira' Douro (Tavares da Silva, pág. I 04), 'o restante raizame, bem como o folhedo e chamiços, juntam-se em caminheiras distanciadas das árvores' Alentejo (SILva PICÃo, I, pág. 40). Parece que la designación se explica por la disposición de 
los montículos en forma de hilera o sea carrera. Relaciónase, pues, con términos como rua $=\mathrm{rug}$ a 'calleja', calle, carrera, via, passata, que encontramos en otras partes de la Romanía con el significado de 'hilera de montículos de hierba', etc. (Hochpyrenäen, C, II, págs. 426, $43^{2-}$ 433). En Trás-os-Montes, caminheira significa 'talhão, sementeira de plantas: caminheira de couves' (Figueiredo).

7. gocha 'paveia de mato, que se junta nos terrenos, para se queimar' Algarve (Figueiredo). Encontramos una definición distinta en el estudio de Estanco Louro, O Livro de Alportel, Lisboa, I929, vol. II, pág. 243: goxa 'pequena superficie coberta de mato no meio de terra limpa; ou con mato denso, no meio de outro mato mais ralo ou pequeno'.

8. toles 'montones redondos de tierra quemada que sirve de estiércol para la siembra' prov. de Lugo (Cuveiro PiÑol); en efecto, han sido registrados últimamente términos parecidos en esa región: tola, entola (con o abierta ), al lado de burrueira, citado en el núm. I ; entolar 'formar tolas' (Ebeling, VKR, V, I 932, pág. ı o6, nota 8); tolas 'montones de rastrojo y tierra que arden en el monte' Sarria-Lugo (RDTP, III, I947, pág. I04). Cf., por fin, Dicc. Acad. Gall, s.v. borrea: tola, toleira. Casi me inclino a creer que se trata de una metáfora humorística, sugerida por el aspecto curioso que, mirados desde lejos, presentan los montones ardiendo en el monte (gall.-port. tolo, tola 'louco, doido, cheio de espanto').

9. raposas 'montoncitos largos de tierra quemada, que reemplaza al estiércol para la siembra' Lugo (Cuveiro Pr̃̃̃ol). Parece que la metáfora proviene de la forma alargada y del color del objeto. Encuéntrase también raposa = 'montón de haces' y 'montón de paja de maíz' en la provincia de Orense (KRüGer, El léxico rural del Noroeste ibérico, Madrid, I947, pág. 62), al lado de zorra (Tenorio, La aldea gallega, pág. 40) y raposa 'espécie de madeiro de trigo de forma retangular (!) e não redonda' Alto Minho ( $R L u, \mathrm{XXV}$, I923-24, pág. I97). Aparece además el rapôso en la "talha" del mato del Minho: "Para o mateiro, que é o trabalhador que enfeixa os molhos, a talha tem mais um molho a que chamam rapôso. O rapôso, como unidade excedente de cada talha, fica de parte, servindo no final para a contagem do trabalho produzido, sem direito a remuneração como mão-de-obra" ( $R L u$, XVI, pág. 274).

Empléase por fin raposa en un sentido muy especial en el Douro y la región de Coimbra: 'terra que os maus cavadores não mobilizam e cobrem com terra puxada do seu corte, para mascarar a terra crua' ( $\mathrm{T}_{\mathrm{A}-}$ vARES DA Silva, págs. 104, 381 : fazer raposas).

He aquí otros términos que se refieren a la combustión de la mata: ı. chamiceira 'monte con la leña medio quemada' Galicia (VAlladaRES) ; cf. berc. chamiza 'restos de plantas y garabullos secos' (GARcía REY), port. chamiços 'acendalhas, lenha miuda, ramos secos', chamiça 'variedade de junco', 'espécie de urze' Minho, 'carqueja' (Figueiredo). 
Estas últimas designaciones se comprenden con claridad, pues denominan las plantas que más particularmente forman parte de la mata de esas regiones $\left(R E W, 335^{\circ}, \mathrm{f} \mathrm{l} \mathrm{a} \mathrm{m} \mathrm{m}\right.$ a $)$.

I I. fogueiro 'montão de herva sêca formado no campo, e que depois se queima para adubo do mesmo campo' Entre-Douro-e-Minho (LEITE DE Vasconcelos, Opúsculos, vol. II, pág. 49I; falta en el Dicionário de FigueIredo). Cf. también fogaratas 'montones de rastrojo y tierra que arden en el monte' Guadalajara, fogata 'hoguera que hacen los campesinos en las huertas con matas de patatas secas' Ciudad Real (RDTP, III, I 947, pág. 98) ( $R E W, F E W$, f o c u s ).

I 2. forniellu 'hoguera que se hace con residuos vegetales en los terrenos que se labran o roturan', forniella, fornelliza 'ceniza del forniellu' (BRAULio Vigón), o bien 'hornillo que se hace de tapines y malezas para quemar la tierra y abonarla' (RATo y HÉviA) en partes de Asturias; forniellu, - $a$ 'montón de broza que se quema en el prado', inf. forniellar, en el bable central (CANELLADA) ; jornillo 'hoguera en el campo para destruir malas hierbas' en el bable oriental (RDTP, III, I947, pág. 96).

forneiro 'queimada, fogueira nos campos, para se adubar a terra com a cinza' Paredes-de-Coira (FIgUeIredo).

fornalheira 'cada um dos montículos de terrões secos, aos quaes se lança fogo para depois espalhar a cinza no terreno, nos campos de feno ou de giesta, quando se quer de novo cultivá-los' Alto Minho ( $R L u, \mathrm{XX}$, I 9 I 7 , pág. 247; falta en FigueIRedo).

Encontramos exactamente la misma denominación — derivados de f u r n u s 'horno' - en los Pirineos aragoneses, fornillo; en Bearn, fornat (hoy día hourne), y en el Macizo Central, fournet, fournèl (Hochpyrenäen, C, II, págs. 24-25; FEW, III, 9o6).

En los Pirineos aragoneses, el tipo forn-se encuentra con derivados de f o r m i c a 'hormiga': forniguero 'haz o montón de leña que, cubierta de tierra, se quema y sirve para abono en los campos' (Pardo Asso); formiguero, tipo que se extiende hasta Cataluña (Hochpyrenäen, C, II, pág. 24). Cf. también port. formigas 'montículos, semelhantes aos formigueiros que se formam sôbre as barachas, as madrizes e as pernas dos corredores das salinas' (R. DE SÁ Nogueira, $A L P, \mathrm{IV}$, I934, pág. I05).

Encontramos, por fin, para designar los pedazos de tierra arrancados, es decir, los t e r r o n es utilizados para hacer los montículos:

tarrois (sing. tarrón) en el bable occidental (AcEvedo, págs. 33, 209: 'hierba que nace en un tarrón o barroco, aunque esté desprendida de la masa de tierra'), forma que corresponde a tarrón y turrón en otras partes de Asturias (Braulio Vigón; Canellada, pág. 347), inf. estarruar 'desterronar' (ACEVEDo) = port. sterroar ( $R L u$, XXVI, I 925-27, pág. 294), torrois, en el este de la prov. de Lugo ( $K K R, \mathrm{~V}, \mathrm{I} 93^{2}$, pág. I I4), tarrón Maragatería (GARrote), terrón 'mata de hierba' Salamanca (LAmano), y terra $\tilde{a}_{O}$, tarräa, turrãa en el Norte de Portugal (LeIte de VAsconcelos, 


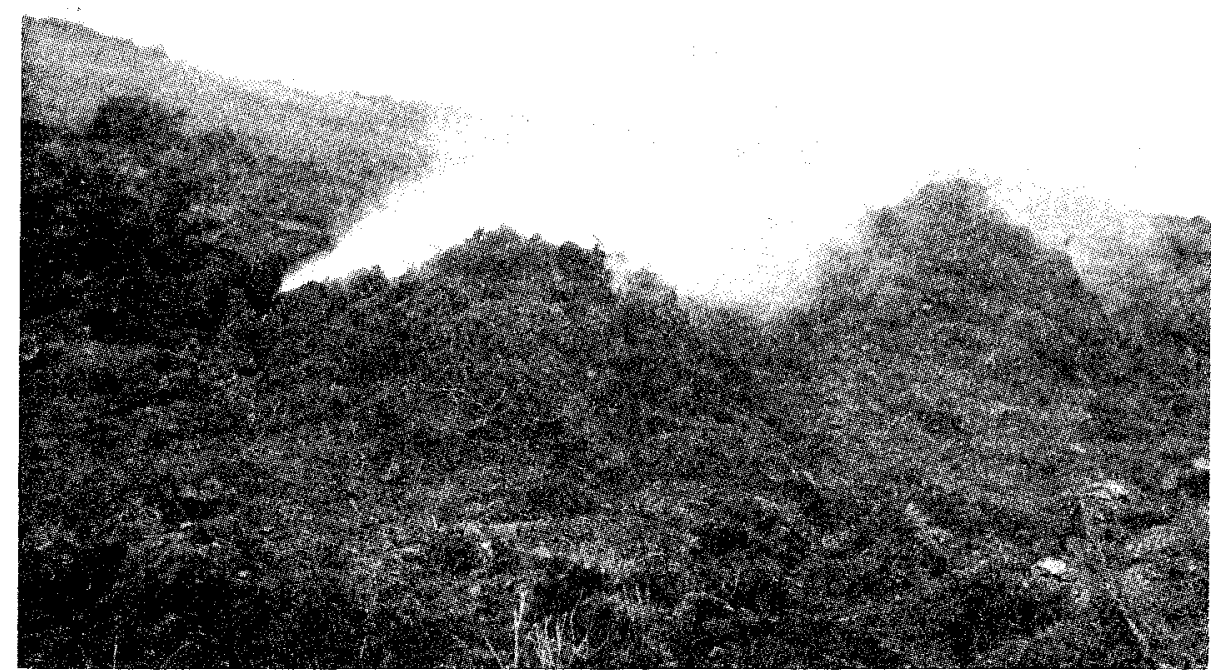

LÁm. 1. La quema del monte en el sudoeste de Asturias. (Foto F. Krüger, Mendoza).

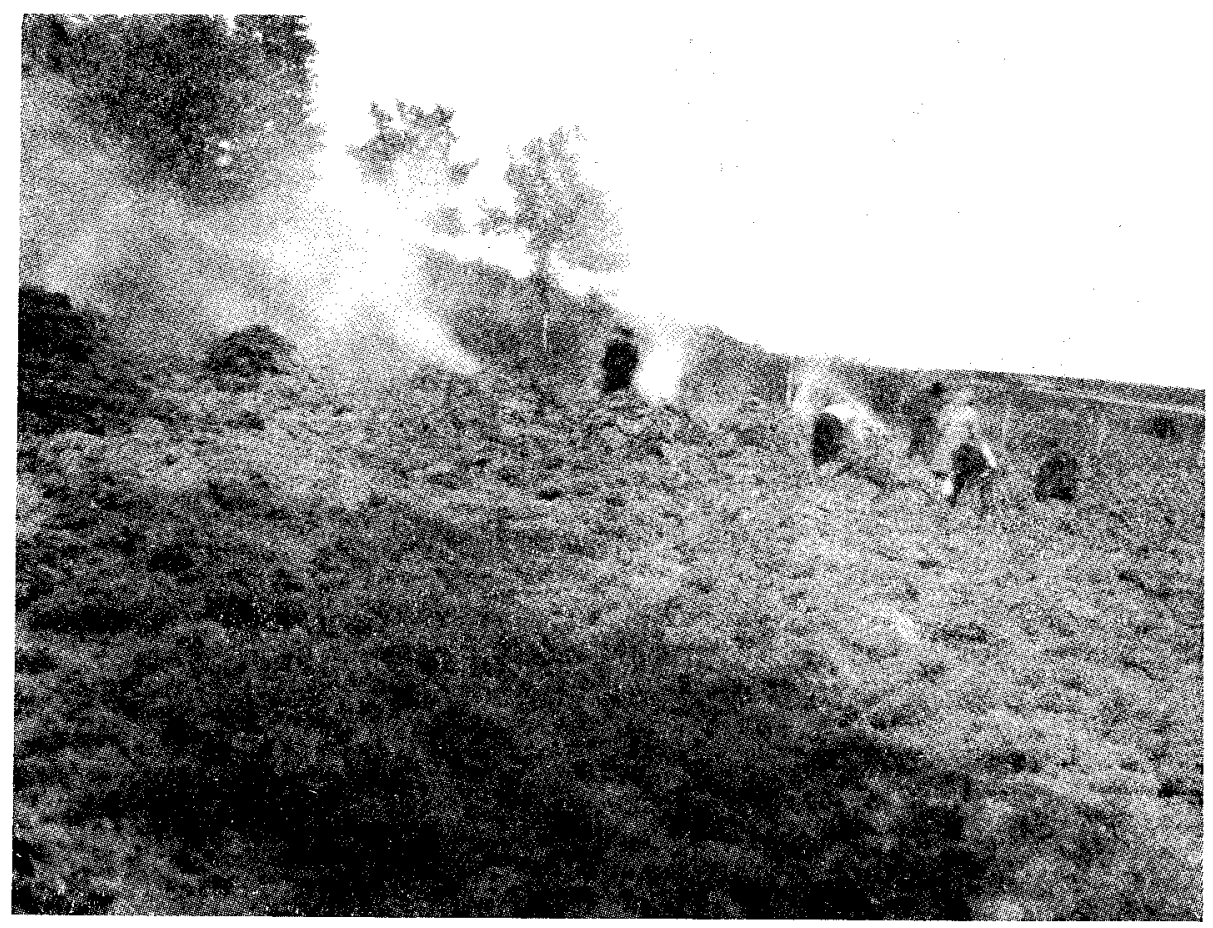

Lám. 2. La quema del monte en el este de la prov. de Lugo. (Foto W. Ebeling, Hamburgo). 


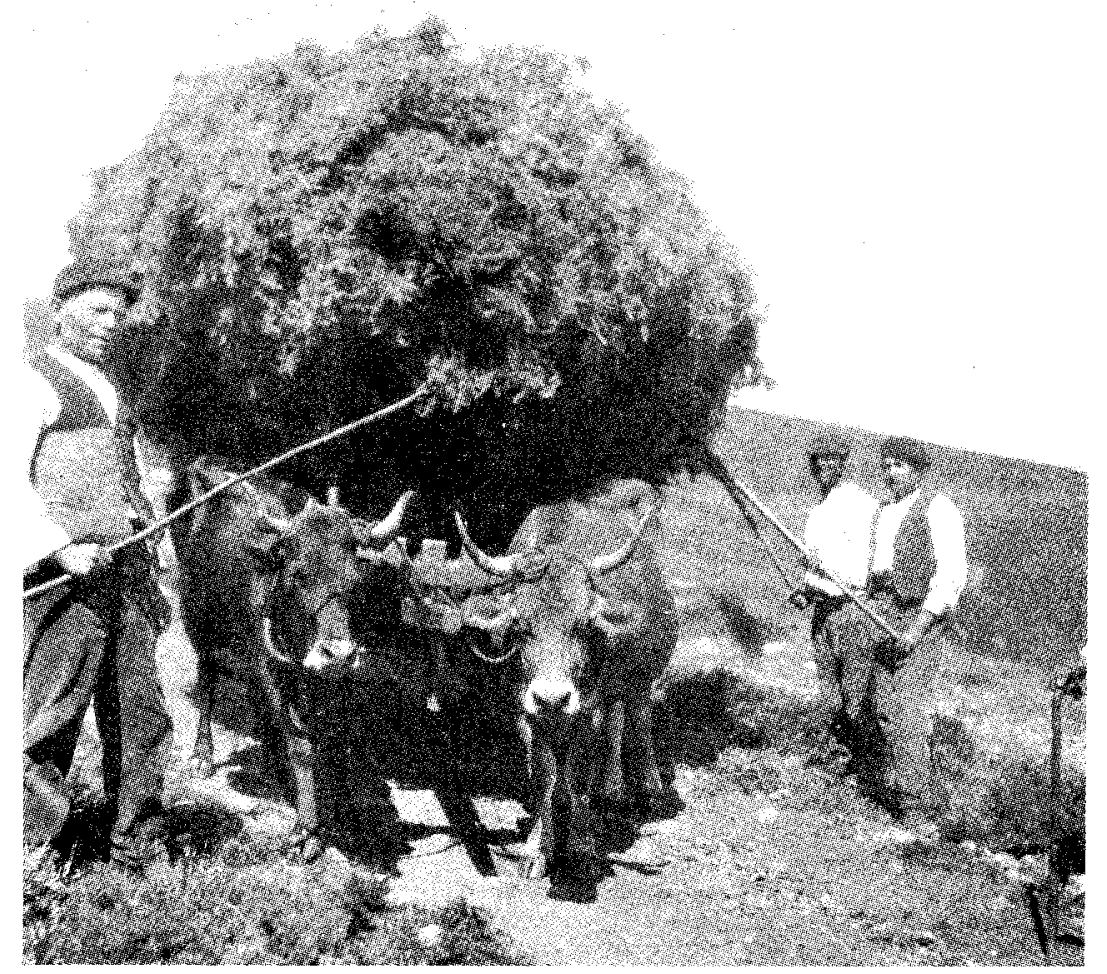

LÁn. 3. Transporte de ramas en el sudoeste de Asturias. (Folo F. Krüger, Mendoza).

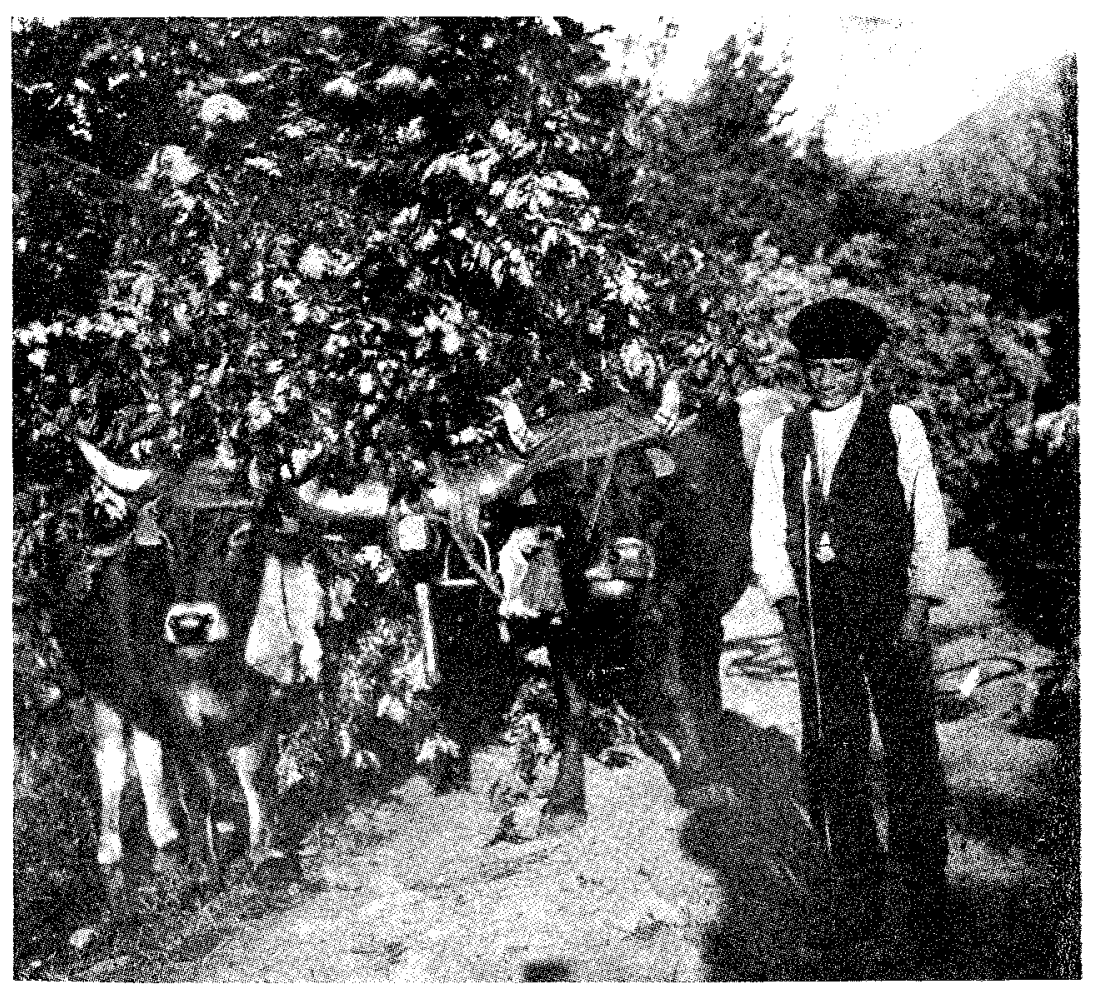

Lám. 4. Transporte de tojo en el este de la prov. de Lugo. (Foto W. Ebeling. Hamburgo). 
Opúsculos, vol. II, pág. 92). Compárense también los verbos correspondientes: estarruar 'desterronar' en el bable occidental (ACEvedo), esterroar, estorroar, sterroar en los dialectos portugueses (VKR, V, I932, pág. I I $4 ; R L u$, XXVI, I $925^{-27}$, pág. 294), etc. y los términos análogos usados en los Pirineos aragoneses y catalanes (Hochpyrenäen, C, II, pág. 26), todos derivados de te r $\mathrm{r}$.

barroeira 'montoncitos de terrón seco, colocado con el césped hacia lo interior, en cuya posición se queman y convierten en ceniza que se extiende por toda la superficie del terreno, cuando se siembra y ara' Galicia (Valladares); véase supra, pág. 235.

barrocos 'trozo de tierra compacta por la humedad y endurecida luego' en el bable occidental (Acevedo, pág. 32), barruecos 'terrones' Besullo (suroeste de Asturias), formas que tal vez pueden considerarse como derivados de barro, tanto más cuanto que encontramos en las inmediaciones gallegas también adoubos = cast. adobes exactamente con la misma acepción (VKR, V, I932, pág. I I 3, nota). Sin embargo, existe también barroco = 'grandes massas de rocha granítica' (Tavares da Silva, pág. 87$)$.

El término que se da a la operación de qu e ma $\mathrm{r}$ mon $\mathrm{te}$ con el objeto de abonar el terreno es generalmente queimar o, en forma sustantiva, queima, queimada. Considerando la importancia que la quema tiene para el cultivo de los terrenos en el Oeste y Noroeste de la Península, no sorprende el gran número de topónimos que se refieren a esta operación, arraigada en la zona montañosa desde tiempos remotos. $\mathrm{He}$ aquí unos cuantos ejemplos:

braña queimada y queimada en el noroeste de la provincia de León (Álvarez, Babia-Laciana, págs. I 56, 205), a queimada 'nombre de un monte' (Cuevillas, Vila de Calvos de Randin, Santiago de Compostela, i 93o, pág. 43), el queimadón, peña queimada Sanabria; la quemadina Cabrera; queimane este de la prov. de Orense (Gegenstandskultur Sanabrias, pág. I 56), queimado (Gomes Pereira, Barcellos, pág. 394), etc. En documentos medievales portugueses: queimatos, siglo XI, queimadoiru, I258; Bauza cremata, $125^{8}$ (Cortesão, Onomástico medieval português, págs. 28o, $4^{8}$ ).

Al lado de queimar, queima aparecen port. boiçar 'roçar e queimar o mato' (Figueiredo), fazer una bouza Bierzo (García ReY) y fazer a bouça (o boucha), Bacia do Coa (Biblos, XII, 1936, pág. 202).

Los significados del vocablo bouza son los siguientes:

bouza 'matorral, jaral' Galicia (Cuveiro Piñol; Valladares; $R L u$, VII, pág. 204), 'matorral de tojos viejos' en la zona gallego-asturiana (Acevedo, al lado de los diminutivos boucia, bouzua).

García Rey registra en el Vocabulario del Bierzo, pág. 55, al lado de bouza, citado arriba, el vocablo boza, frecuente en las Ordenanzas, y que evidentemente representa una forma castellanizada $=$ 'terreno comunal 
que los vecinos de un lugar o pueblo aran y siembran para beneficiarse de sus productos'. Explícase esta última acepción por una costumbre profundamente arraigada en determinadas zonas del Noroeste, más particularmente en el Bierzo, en la Cabrera y Sanabria. Descríbela Casado Loвato, El habla de la Cabrera Alta, pág. 44, de la manera siguiente: bouza 'terreno en el monte, roturado por primera vez para cultivo, que siembran y recogen en común; en algunos pueblos sortean la bouza cada cuatro o cinco años, repartiendo un trozo a cada vecino que lo cerca y cultiva individualmente'. A esta misma costumbre se refieren J. Aragón en su novela Entre brumas, Astorga, I92 I, pág. III : bouza 'terreno en el monte procedente de reparto comunista, que roturan y dedican para el cultivo' y S. A. Garrote, El dialecto vulgar leonés, $2^{\text {a }}$ ed., Madrid, I947, pág. I6r. Se explica por dicha costumbre también la acepción que el vocablo bouza ha tomado en la Sanabria colindante: 'tierra no cultivada, pero roturada por primera vez para cultivo'.

Se encuentra la palabra boiza (= bouza), al lado de boixa, boucha (Figueiredo), también en el norte de Portugal, ya en el sentido primitivo de 'mata', ya con un significado que deja vislumbrar que allí también la boiza se destinó a la roturación y al cultivo:

bouça 'terreno com tojo, giesta, pinheiro, e às vezes carvalho' Coura (Leite de Vasconcelos, Opúsculos, vol. II, pág. 476), 'pinhal, mato' Minho (Tavares da Silva, Esboço, pág. 95, al lado del sustantivo deverbal esboiça 'terreno com o mato cortado e queimado, pronto para ser semeado em cru' Douro). Cf. también carraboiçal 'ladeira penhascosa, sobretudo cheia de silvas e outro mato' Trás-os-Montes $(R L u, \mathrm{~V}$, pág. $\left.3^{6}\right)$.

bouça 'terreno ou plano onde o mato, os pinheiros e chaparros crescem livremente' Vila do Conde ( $R P F$, II, I947, pág. I 33 ).

bouça 'pedaço de monte, vedado (!), onde cresce mato ou arborizacão' Alto Minho ( $R L u, \mathrm{XIX}$, I9I6, pág. I96; XIV, pág. I49; XVI, pág. 220); 'terreno de mato, murado (!) e com algumas árvores' Minho (TAvares da Silva, pág. 95); encontramos el mismo significado en Salamanca: boiza 'terreno cercado (!), grande, de mediana calidad' (Lamano).

En la región de Barcelos, bouçò, bouçós y boucinha designan un campo cultivado, pero subsiste también la acepción bouça 'terra bravia ou de mato mais ou menos cercada de parede' (!) (Gomes Pereira, Tradições populares, linguagem e toponymia de Barcellos, Espozende, I9 I6, pág. 3Io).

Cabe agregar, por fin, el verbo boiçar 'roçar e queimar o mato' (FIGUEIREDo), esboiça, citado arriba, y - con sentido algo distinto, aplicado a la viticultura-esbouça, esbouçar 'surriba profunda para a plantação de bacellos' (J. Moreira, Estudos da lingua portuguesa, $2^{a}$ ed., Lisboa, I922, vol. I, pág. I 97$)$.

Como el vocablo bouza ha tomado muchas significaciones (en partes 
del Noroeste $=$ 'terreno comunal', debido a las prácticas colectivas vinculadas con el aprovechamiento de tales terrenos), no es fácil distinguir cuál de los matices predominó en la creación de los t o pó n i mos respectivos. Sea como fuere, el número de nombres toponímicos de esta categoría difundidos por todas las sierras del Noroeste es incalculable. He aquí unos cuantos ejemplos:

En nombres de lugares: Bouza, Boza Asturias; Bouza, Bouzo, Bouzoa, Bouzón, Bouzaboa, Bouzavella, Bouzamelle, Bouzabrañas, Bouzaschás, etc., Galicia; San Juan de Bouzas prov. de León; Bouza Salamanca, etc.

En nombres de montes, etc.: la bouza, las tierras de la bouza noroeste de León (Álvarez, Babia-Laciana, págs. I 55, I95); Bouza Maragatería (GARrote, pág. I6I); la bouza del rojo, las bouzas Cabrera; boucelo Bierzo; bouzuelas, caño bouzuelas Sanabria.

La posesión de una bouza (o de varias bouzas) tenía y tiene todavía hoy gran importancia para los pueblos del Noroeste. Así se explica la frecuencia con que aparece en la toponimia de determinados lugares. Es particularmente instructiva la nómina establecida por A. Gomes Pereira (en su libro antes citado) para el distrito de Barcelos. Casi no hay lugar de esta comarca en cuya toponimia no aparezca este nombre tan significativo: Bouças (pág. 389), Bouços (pág. 332), Bouça Nova (pág. 342), Bouça (págs. 344, 38 I, 383, 39 I), Bouça Redonda (pág. 348), Bouça Grande (págs. 354, 373), Bouça da Ponte (pág. 394), Bouça do Rio, Boucinho (pág. 40 I), Boucinha (págs. 385, 387).

Corresponde a la abundancia de bouza en la toponimia actual la frecuencia con que aparece ya en el onomástico medieval: Bauzas, 944; Bauzolinas, 907; Bouzola, siglo xi; Bauza cremata, I 258; Bauza de lobo, I 258; Bauzoos, I220, I 258; Bouza moliada, I $25^{8}$ (Cortesão), Bouteae, Boutiae = Boeza, Boza, Bouza, Bousa, etc., en la toponimia actual, registrados en inscripciones latinas (HMP, III, pág. 274), etc.

La etimología de bouza ha sido discutida por varios romancistas. J. Leite de VAsconcelos, Estudos de philologia mirandesa, Lisboa, igoo, vol. I, pág. 355, rechaza con buenas razones la etimología b a ls a presentada por Ad. Coelho, sin llegar a una solución difinitiva. Pocos años después, en i 9o6, A. R. Gonçalves Viana argumentó en sus Apostilas aos dicionários portugueses, vol. I, pág. I 65 , que "esta palavra, formalmente, parece provir de $\mathrm{b}$ a I t e a, plural neutro do adjectivo balt e us $=$ "o que cinje'". En cambio, Américo Castro, en el artículo dedicado a esta palabra en $R F E$, V, I9I8, pág. 31, da "como mera hipótesis" la forma boutius, refiriéndose a nombres ibéricos, como boutius, b o u t i a , citados por Leite de Vasconcelos. Contradicen, sin embargo, las formas más antiguas (Bauzas, etc.), que presuponen un grupo vocálico au. Así parece a primera vista más acertada la opinión de MeyerLübke ( $R E W, 919)$, quien se adhiere a Gonçalves Viana, traduciendo minh. bouça por 'Bannwald'. En efecto, esta definición corresponde en algo a la realidad, según demuestran los ejemplos citados (= 'mata cer- 
cada', etc.). Pero no sé si tal significado especial, que no se encuentra en ninguna otra parte de la Romanía y que existe al lado de bouza = 'matorral, jaral en general', permite establecer una vinculación semántica con b a lte us 'cintura, cinturón'. Habría que saber en todo caso si bouça = 'mata cercada' representa el sentido original del vocablo.

También me parece difícil presuponer para los vocablos del Oeste la evolución semántica revelada en $F E W$, I, 226, en los dialectos galo-romances ( $>$ 'rocher saillant, précipice') y con la que concuerda perfectamente el cat. bals 'despeñadero' (Dicc. Alcover), pues, exceptuando carraboiçal, citado arriba, no encontramos en los dialectos occidentales ningún vestigio que justifique tal suposición.

Considerando estas dificultades, me inclino a creer que bou६̧a bouza representa una raíz prelatina * b a u t t i a. Partiendo de bouçar, boiçar 'rozar el monte, vale decir, dar la primera roturación a un terreno' se comprende perfectamente la aplicación de este término al primer espadamiento que se da al lino: gall. debouzar, debouza (VAlladares), trasmont. debouçar, chabouçar, minh. rebouçar, arrebouçar (Gegenstandskultur Sanabrias, pág. 250; Messerschmidt, VKR, IV, I93I, pág. 287 ). Encontramos estos términos en el extremo Noroeste, es decir, justamente en la zona en que predomina bouza en su acepción original y en la toponimia.

Hemos observado antes que bouça se emplea a veces en el sentido especial de 'pedazo de monte vedado, o sea cercado'. Encontramos exactamente la misma acepción en las siguientes voces:

llendón 'terreno para rozu y para llevar ganado a pastar; no se siembra', inf. llendar 'cuidar de que el ganado no se salga de un prado o de un llendón', llende 'lugar donde se llenda el ganado' (CAnellada, Cabranes, pág. 252), vocablos que corresponden perfectamente a llindiar en el conc. de Oviedo y allindar en el asturiano occidental $=$ 'cuidar de que el ganado que se apacienta en una heredad no traspase determinados límites' (Braulio Vigón, s.v. llendar). Trátase, pues, evidentemente de derivados de $R E W, 5048$ li m es, 505 I l i m it a r e.

zarrado 'terreno inculto con árgoma y pinos que, generalmente, está cerrado con pared' en la zona occidental de Asturias (Acevedo) ; zarrar $=$ 'cerrar'.

coutada 'parte cotada del monte para que paste en ella el ganado vacuno' prov. de Orense (Tenorio, op. cit., pág. 20) = port. coitada 'terra defesa; cerrado'; trasmont. couto 'terreno em que é vedado apacentar gado' ( $R L u, \mathrm{XX}, \mathrm{I} 9 \mathrm{I} 7$, pág. I 55) ; sanabr. couto 'pradera prohibida del pasto' (Gegenstandskultur Sanabrias, págs. I 54, I 58 ), frecuentísimo también en la toponimia: Couto, Couta, Couteiro, Coutadas prov. de Lugo (Nomenclátor, pág. 333), etc. ( $R E W$, I 784 c a u t u m).

devêsa 'bouça ordinariamente murada' (Gomes Pereira, Tradições populares de Barcellos, pág. 3 I I), 'mata' Trás-os-Montes ( $R L u$, III, pág. 74), debesa 'porción de tierra acotada para pasto o leña' Galicia 
(Valladares), 'porción de terreno dedicado a pastos o montanera' Maragatería (GARrote), 'cacho de monte donde van a pasturar' Sanabria, etc. Muestran estos ejemplos el empleo de d e f e n s u m, $R E W,{ }_{25}$ I 8 , $F E W$, en su sentido original.

Cabe agregar, en fin, el término cachada, que en Galicia significa 'monte o terreno inculto que se cava y quema para convertirlo en labrantío' (Carré Alvarellos, vol. I, pág. 3o9; Dice. Acad. Gall.) y 'quema de un pedazo de monte para sembrarlo de trigo o centeno' (Cuverro PiÑol; Valladares). Encontramos la primera acepción también en el Norte de Portugal: cachada 'campo que proveio de mato; rôça' (Leite de Vasconcelos, Opúsculos, vol. II, pág. 477 ), = 'logar ou campo em tempo bravio e depois arroteado, reduzido a cultura ou cachado', diminutivo cachadinha (Gomes Pereira, Barcellos, págs. 3 Io, 381, con referencias a nombres toponímicos), 'leira, terras cachadas ou arroteadas; acto de cachar ou arrotear; frecuentemente toponímico' Alto Minho ( $R L u$, XIX, I9i6, pág. 200), 'alqueive; queima do mato' (FigueireDo). En contraposición a roza, que significa 'un monte o matagal en su estado natural, extenso, o por lo menos ilimitado', el término cachada designa 'un pedazo de monte preparado para la roturación'. El verbo cachar 'quemar y preparar un pedazo de monte para sembrarlo' Galicia (Dicc. Acad. Gall.), 'arrotear, desbravar', 'limpar um campo de pedras, cavando-o', 'surribar' en el Norte de Portugal (Figueiredo; Leite de Vasconcelos, Opúsculos, vol. II, pág. 477 ; $R L u$, XIX, I9I6, pág. 200 ; Tavares da Silva, Esbôço, pág. I oo) y el sustantivo cachada (en la Cabrera un cacho de faceira = 'un pedazo de sierra') se relacionan con cacho 'pedazo, pequeña parte, fragmento', combinándose la idea de 'cavar', 'arrancar los vegetales' con la de 'desmenuzar', 'destrozar'; cf. salmant. cachar 'partir, hacer cachos una cosa' y la forma compuesta cachipodar 'podar las ramas' (LAMANo). Corresponde perfectamente a esta acepción el gall. cascada, mencionado por VAlladares, s.v. cachada; gall. cascar 'romper, cascar'.

El empleo de cachada en el sentido indicado arriba parece que se limita a Galicia (o partes de Galicia) y el Norte de Portugal. Cuadra con esta área la repartición de topónimos del tipo cach-, la cual abarca, según las observaciones de J. PIEL, Os nomes germânicos na toponimia portuguesa, Lisboa, 1937, págs. 57-58, esta misma región (docenas de ejemplos en el Minho).

En cuanto a la etimología de cach- = 'pedazo', etc., me inclino a aceptar la propuesta por Meyer-Lübke, $R E W$, 694 I $a$ q w a ch, forma onomatopéyica. Pero esta opinión no la comparte Brüch, que en un artículo publicado en $Z R P h$, LVII, I937, pág. 586 propone una base * c a c c a lus, ni el FEW, II, 805, que relaciona esp. cachar con c o a c t a r e = 'apretar', acepción que no corresponde al sentido de la palabra castellana.

En cuanto a cachada, cacheda, cacheira, cachela, cachotera, emplea- 
dos en Galicia con el sentido de 'hoguera, hoguera grande, hoguera con grandes llamas' (RDTP, III, I 947, pág. I 04), cachela 'hoguera que se hace la víspera de San Juan' (Dice. Acad. Gall.), cachèira 'gran fuego en el hogar' (VALladares), no sé si deben relacionarse con cachada= 'quema de un pedazo de monte', o si es preferible derivarlos de otro matiz semántico de la gran familia cach-: cf., por ejemplo, gall. cachoar 'hacer espuma un líquido; hervir el agua a borbollones' (VAlladares).

Gall.-ast.-port. cadaval 'tojal quemado, pero que conserva aún en pie los troncos medio carbonizados de los tojos' (Valladares; Rato y HÉvia; Braulio Vigón; Canellada; Figueiredo) se relaciona con cádava 'tronco o remate de tojo chamuscado', vocablo tal vez de origen prelatino, común a los dialectos citados (al lado de cáveda en ciertas zonas de Portugal, según Leite de VAsconcelos, De terra em terra, vol. I, págs. I 7 I, 209); según del Dice. Acad. también = 'urce'. cadaval es frecuentísimo en la toponimia del Noroeste y del Oeste: port. Cadaval, i 258; Cadavaes, I 208 (Cortes̃̃o, pág. 63), Cadavo, Cadaval, Cadaveira, etc.

Después de quemado el monte, se extiende la ceniza por tierra, y así sirve ésta de abono. Luego que sobrevienen las primeras lluvias, sigue la siembra, y se cubren las semillas con la azada o por medio del arado, según la calidad del terreno. En partes del Noroeste (Bierzo, Lugo, suroeste de Asturias) utilizan para la primera roturación del monte rozado el a rado primitivo de gancho, o sea arado-cuchillo, llamado por su forma curva cambela (Gegenstandskultur Sanabrias, págs. I 84-I 85; EbeLing, VKR, V, I932, págs. I04-ı05;Hochpyrenäen, C, II, págs. I I 4-I I6; J. Caro BaroJA, Los arados españoles. Sus tipos $y$ repartición, RDTP, V, I949, pág. 46).

La porción de terreno recién roturado se llama arroto en la Maragatería, arrote en la Bañeza (GARROTE), port. arroteia (Figueiredo, derivado del verbo arrotear), vocablos que corresponden a port. romper matos 'roçá-los e desmoutá-los' ('TAvares da Silva, pág. 396 ) y a los que se agregan nombres toponímicos, como rotêa, atestiguado ya en 1258 (Cortesão, pág. 299) y que sobrevive hasta hoy al lado de arrotea 'terra antes inculta que se arroteou ha pouco' en el Minho (Gomes Pereira, págs. 39 I, 396); rumpidas en el noroeste de la provincia de León (Álvarez, Babia-Laciana, pág. I9o), etc.; cf. cast. rompido, Segovia rompizo 'terreno recién roturado' (RDTP, II, I946, pág. 633), cat. rompuda (Hochpyrenäen, C, II, pág. 24), etc.

II. ALGUNAS DESIGNACIONES DEL TRONCO DE LA BERZA: TUERO, TROCHO, TRONCHO, TOUZO, ETC.

En su tesis sobre el habla de la Cabrera Alta, la Sita. M. C. Casado Lobato registra (pág. 59) el vocablo truexo usado en dicha comarca con la acepción de 'troncho, tallo de las hortalizas', y lo explica por un cruce entre *trunculus y torus. Nos remite al estudio que Vicente 
García de Diego dedicó hace años a unas cuantas voces de significado parecido ( $R F E$, XI, I 924, págs. 346-348), sin llegar a conclusiones definitivas. Por esto me parece conveniente volver al problema, escogiendo como punto de partida la terminología que presentan las hablas del Oeste.

Son variadísimas las designaciones que dan en los dialectos occidentales al tallo de las hortalizas:

I. tuero 'tronco de la berza' Sanabria central y septentrional; turungallo, al lado de tuero, San Ciprián de Sanabria; toro en la zona gallega de Sanabria; tuero en el Valle del río Ibias y otras zonas asturianas (MUNTHE 'trädstam'; RATo Y HÉvia, BRAULIO VIGóN 'troncho, tronco') ; tueriu Cabranes (Canellada).

toro 'pedaço de qualquer coisa, geralmente de forma arredondada, cortada em sentido transversal' Minho ( $R L u$, XVI, pág. 276); port. toro 'segmento de tronco ou ramo de pinheiro, de comprimento variável entre 5 a 6 palmos, geralmente destinado a combustível' ( $R L u, \mathrm{XVI}$, pág. 276 ) ; gall. toro 'troza, tronco aserrado por los extremos, para hacer después tablas', tora 'pedazo de una cosa cortada de otra: porciones de ciertos pescados, etc.' (VAlladares), torada 'trozo, pedazo de árbol, de regular dimensión, que se corta del tronco, para hacer tablas' (Cuveiro PiÑol); ast. tueriu 'tronco de un árbol en su parte más gruesa o de la berza' Cabranes (CANellada, pág. 36o) ; tueros 'pequeños trozos de tronco de árboles, dispuestos para la fabricación de albarcas' prov. de Santander (Alcalde del Río, pág. 24); torello 'cada pedazo que resulta de cortar un árbol horizontalmente' Ribagorza (FERRAz y CASTÁN).

Registra el Dicc. Acad. el vocablo tuero con la acepción de 'trashoguero, leño grueso' = 'bûche de bois', significado que encontramos en Extremadura (Coco, RCEE, XIV, I940, pág. 284 'trozo de leño grueso').

En la zona oriental de Sanabria apunté tuero 'hueco de un árbol', significado que parece corresponder a tuera 'hueco o cavidad que hace la carcoma en el tronco de un árbol' prov. de Santander (García-LoMAS).

REW 88I i t o r u s Aebischer, $B D C$, XVIII, 1930, pág. 212.

2. tuerto 'tronco de la berza', recogido esporádicamente en la Cabrera Alta, parece ser una desfiguración del tipo I (cruce con tuerto).

3. troso 'pie de la col vieja' Galicia (Valladares), trô̧̧o 'parte de la planta del maíz' Baião (Leite de Vasconcelos, Opúsculos, vol. II, pág. 499), troços 'variedades de couve de pé alto, muito abundante, que se vai desfolhando á medida que vai crescendo' Minho ( $R L u, \mathrm{XIV}$, pág. I 68), trô̧̧o 'caule erecto, mais ou menos consistente, de planta herbácea: um trôço de couve' Turquel ( $R L u$, XXVIII, I93o, pág. I3I). 
trôço 'a extremidade mais grossa da árvore depois de cortada' Alto Minho ( $R L u$, XXX, I932, pág. I95).

trộo 'erva ou palha traçada ou cortada' (FigueIredo).

No cabe duda que en todos estos casos se trata de una parte de una planta, hierba, árbol, etc. Hay que relacionarlos, pues, etimológicamente con cast. trozo 'pedazo', trozar 'dividir en trozas el tronco de un árbol', troza 'tronco aserrado', and. troza 'cada una de las raíces gruesas de un árbol que se extienden hacia el exterior' (Alcalá Venceslada), cat. tros 'trozo, pedazo' > 'terra de regadiu', 'campo' (Griera, Tresor, XIV, pág. I73), prov. tros 'tronçon, trognon d'un chou' (LÉvy), troussèu 'trognon de chou', ant. fr. tros (Gamillsaheg, EWFS 87o, REW 8725 thyrsus, *tursus). Queda sin explicar la -z-del castellano; es inadmisible la etimología propuesta por García de Diego, RFE, XI, I924, pág. 347 (trozo se relaciona con t or os us, de to r u s 'pedazo redondo'); hay que pensar tal vez en un cruce con tronzar, de ${ }^{*} \mathrm{tr}$ u nc e u s${ }^{2}$.

4. troncho 'tallo de las verduras', al lado de trocho Bierzo 'caule da couve' Baião (Leite de VAsconcelos, Opúsculos, vol. II, pág. 390), troncha 'couve tronchuda' Minho (RLu, XXXIX, I93I, pág. 270).

troncho 'tallo de las hortalizas' (Dicc. Acad.) > cat. tronxo.

$R E W 8955$ *t r u n culus.

5. trocho 'tronco de la col' en el sureste de Orense y Hermisende (zona rayana de Sanabria) ; 'tronco de la berza' y 'trozo de leña' en el Bierzo (García ReY), al lado de troncho 'tallo de las verduras' (González y Morales) ; tróchos 'troços; pé de couve cortado rente ás folhas' Minho (Boaventura, Vocabulário minhoto, pág. I45), 'caule, pau' Trás-osMontes ( $R L u, \mathrm{XXXV}$, I937, pág. 293), al lado de troncho, -a (Leite de Vasconcelos, Opúsculos, vol. II, pág. 39o: Baião).

Como en el grupo 4, predomina la idea de 'tallo, tronco'. Hay que notar además la vacilación entre trocho y troncho que se observa en diversas regiones. Parece, pues, que trocho reoresenta un cruce entre troncho (que es el sentido original de la voz) y trozo.

Aparece la misma palabra con la acepción de 'palo corto' en el oeste de Asturias (Acevedo), 'leño partido' en el Valle del río Ibias, 'palo pequeño, generalmente de piorno o de urz; se utiliza para atizar la lumbre' (Álvarez, Babia-Laciana, pág. 335), 'palo corto, trozo de leña' en el Bierzo, 'cuña' en la zona occidental de la prov. de Lugo (VKR, VI, I933, pág. Io I), troicho 'não é um pau ou vara qualquer, mas um pedaço tôsco, um bocado de um fueiro, etc.' Minho (RLu, XXIX, I931, pág. 270).

2 tronza 'cada una de las partes en que queda dividido el roldo después de aserrado' Bierzo (García REY), tronce 'acción de tronzar la madera; corte transversal en un tronco' en el bable central (Canellada), cast. tronzar 'dividir, quebrar o hacer trozos'. 
Opino que hay que separar este grupo de los ejemplos anteriores. trocho = 'palo' pertenece más bien a la familia tocho, usado con el mismo sentido ('palo') en el Noroeste de la Península y del que encontramos huellas también en el Oeste (Salamanca, ant. port. tocho); véanse los detalles en Hochpyrenäen, B, I6. La $r$ postconsonántica de las formas occidentales se explica como $r$ epentética, tan frecuente en las hablas del Oeste.

6. troxo ( $x=$ fricativa palatal sorda) 'tronco de la berza' Bierzo y este de la prov. de Orense.

truexo Cabrera Alta, Cabrera Baja, Sanabria central.

truejo ( $j=$ fricativa velar sorda) 'berza' Limianos-Sanabria, 'conjunto de berzas' San Ciprián de Sanabria.

Indican el significado y la repartición geográfica que el grupo troxotruexo está íntimamente vinculado con trocho (5). En cuanto al diptongo, compárese fluexo 'flojo' en la misma región (Guzmán Álvarez, Babia-Laciana, pág. 294).

7. touzo 'tallo de la berza' Besullo (suroeste de Asturias), 'tallo de las plantas' noroeste de León (Álvarez), touza, toza 'parte del tronco de un árbol; se destina con ramas para combustible', atouzada 'leña arrancada con la raíz o touza' Bierzo (GARcía REY), touza 'parte inferior, cerca de la tierra, de las hierbas, cereales, árboles' Maragatería (Garrote).

touça, toiça 'pernada alta e grossa de qualquer árvore' (FIgueIredo), touço, - $a$ 'vara alta e grossa' (Gomes Pereira, Tradições populares de Barcellos), términos recogidos en el Minho; 'vergontea de castanheiros' Minho (Boaventura, Vocabulário minhoto), port. touça 'a cabeça da árvore explorada em talhadio' (TAvares DA SILva).

Encuéntrase la misma voz en el Brasil: touça 'o pé das canas de assucar, donde elas nascem filhadas; grupo de plantas de uma só especie', touceira 'grande touça' (Pereira de Costa, Voc. pernambucano); = toiceira 'pé de uma planta, com raízes' Terra do Fundáo (Figueiredo).

Concuerdan con el significado de 'tallo, tronco' las acepciones siguientes:

touzo 'parte inferior del eje del molino de agua' Santiago de Compostela (véanse también Valladares y Cuveiro Piñol), Melide (Risco, pág. 388$)$.

toiço 'timón del carro', 'parte do carro, donde sai o cabeçalho' Serra da Estrêla, Beira (Messerschmidt, VKR, IV, I931, pág. I50), 'cabeço' Minho (Boaventura, Vocabulário minhoto).

Hay que advertir, sin embargo, que existen también formas con $r$ : trouso 'eje vertical del molino' Borneiro (J. Lorenzo Fernández, Bol. de la Comisión de Monumentos de Orense, XIII, separata, pág. I4), trousa 'timón del arado' trouso 'dental del arado' Lugo (VKR, V, I932, págs. I о4, I 1 o) como en el Bierzo (Gegenstandskultur Sanabrias, pág. I 88). Trátase de la $r$ epentética tan frecuente en los dialectos occiden- 
tales, y de la que encontraremos otros vestigios en el transcurso de este trabajo.

port. touça 'feixe do lagar' (TAvares DA Silva).

Relaciónanse estrechamente con el sentido de 'tallo, parte inferior de las plantas' los vocablos siguientes:

touças 'terrenos com arvoredo ou mato denso' Trás-os-Montes ( $R L u$, XXXV, I 937, pág. 29I), 'tufo de ervas ou de mato' Minho (BoavenTuRA, Vocabulário minhoto), 'moita de feno grosseiro' Trás-os-Montes ( $R L u, \mathrm{~V}$, pág. i o7; Figueiredo), 'moita de carvalhos' (Figueiredo), 'mata, mato, matagal' Miranda (Leite de VAsconcelos, Estudos de philologia mirandesa, vol. II, pág. 223); touza 'arbusto; arboleda en donde se cría madera para arcos, etc.' Galicia (VAlladares, Cuveiro PIÑol), 'matorral; terreno inculto e incultivable' San Ciprián, 'bosque de robles' en la zona occidental y meridional de Sanabria y en la zona colindante de Orense.

touza 'parte inferior de las hierbas' Maragatería (véase supra), ast. tozón 'yerbas malas que, secas, se quedan en la tierra e impiden el nacimiento de las siembras' (RAto y HÉvia), ast. tazón 'caña de maíz que queda en pie después de cortada' (García de Diego, RFE, XI, I924, pág. 346$)$.

touça 'vinha rasteira, vinha prostata' Minho (TAvares DA Silva, pág. $\left.43^{\circ}\right)$.

Explícanse a raíz de los significados mencionados ('mata, robledal', etc.) los topónimos siguientes, tan frecuentes en el Noroeste de la Península: Touza I 258 (CoRtes̃̃o, Onomástico medieval português), Touza en Galicia, Touza Redonda 'eido cultivado' (Cuevillas, Randin, pág. 42 ), touza scura, touza raposa, touzaca en Sanabria (Gegenstandskultur Sanabrias, pág. I 57 ), etc.

Llama la atención el hecho de que todos los significados registrados en el núm. 7 se encuentren únicamente en el Oeste y en el Noroeste de la Península (y en el Brasil). Acierta Meyer-Lübke, $R E W$ 8602c, cuando supone una base prelatina: * t a u t i a, mejor dicho * t a u t t i a .

Pertenecen a la misma familia:

a) retoiçar 'comer, pastando, falando-se de animais' Minho (A. Braga, Provincialismos minhotos) = 'pastar en la toiça'.

b) retouçoar 'respigar' Alentejo (TAVARES DA Silva, pág. 392), retouzar 'retozar', retouzo 'segunda pacedura del otoño' noroeste de León (Álvarez, Babia-Laciana, pág. 326) = 'retoñar'.

Según la ingeniosa hipótesis de K. JABERG, $R P F$, I, I947, pág. Io, habría que incluir en el grupo $b$ ) también port. retoiçar 'brincar' $>$ 'balançar, baloiçar' (y su derivado retoiça 'baloiça' que existe al lado de redoiça, reloiça): "retoiçar pourrait avoir eu le sens de 'pousser des rejetons', d'où l'on serait arrivé aux idées de 'luxuriant, lascif, gaîté', enfin à celles de 'folâtrer, sauter, jouer' ", cambio semántico que se observa en 
efecto en otras lenguas romances. Pero surge una dificultad, y es que reto$z a r$, usado en el sentido de 'saltar, etc.', se encuentra también en castellano, es decir, fuera del área de toiça 'arbusto, mata, etc.' y en catalán, donde retossar significa 'saltar els animais donant-se cops de cap' (GrIERA, Tresor, XII, pág. I68). Parece seguro que hay que buscar en esta última acepción el punto de partida de retozar, usado en el sentido general de 'saltar'; véase más abajo lo dicho sobre el sentido especial que ha tomado toza etc. en la zona catalana-aragonesa.

Forman un grupo semántico aparte:

toza 'viga grande de la que se sacan las tablas', 'dintel' Salamanca (Lamano), toza, al lado de troza, 'dintel' Mérida (Zamora Vicente, págs. I 4I, I 42), toça, torça, tórsa 'padieira da porta', 'verga da porta' Beira (Gomes Pereira, Guarda, pág. 66; Gomes Pereira, Penedono, pág. 55; Figueiredo), toza Orense, al lado de troza, trouza 'dintel de la puerta' Sanabria (Gegenstandskultur Sanabrias, pág. 73), minh. tronça 'trashoguero' (FigueIRedo), cast. toza 'pieza grande de madera labrada a esquina viva' (Dicc. Acad.), toza, tosa, tos 'bloque de madera; se llaman así las que llevan de América y otras partes, de maderas finas, para aserrarlas y hacer muebles' (Lugo, Colección de voces y frases provinciales de Canarias, págs. I 62, I63).

Muestran los ejemplos citados que hay que distinguir dos tipos diversos: a) el tipo toza, b) los vocablos caracterizados por el elemento consonántico $r$, propios de las hablas del Oeste. Trátase en este último caso de la $r$ epentética tan frecuente en los dialectos occidentales (cf. pág. 249 tocho-trocho, pág. 247 trouso).

Llama además la atención la vocal tónica $o$ en ciertas regiones del Oeste (toza Orense); indica este detalle que las voces no pueden relacionarse directamente con touça, toiça citadas al principio de este capítulo. Parece más bien que se trata de términos importados de fuera (¿Castilla?) por el habla de los carpinteros.

Quedan por fin toza 'en algunas partes, pedazo de corteza del pino y otros árboles' (Dicc. Acad.), arag. toza 'tocón, chueca o trozo que queda a la raíz del tronco, ya arrancada o en la tierra aún' (Borao; PARdo Asso), vocablo con el cual se relacionan tozuelo 'cabeza' en La Litera (Coll y Altabás) y Aragón (Pardo Asso; Kuhn, RLiR, XI, I935, págs. I93-I 94), 'frente' Graus (Badía MARGarit, pág. I 88), tirar a toz 'tirar los bueyes uncidos por el testuz' Aragón (Pardo Asso), toza 'yugo con que se uncen las mulas al arado' Ciudad Real (Dicc. Acad.), cat. tos 'la part del cap oposada al front; el front del bestiar, etc.' (Dicc. Aguiló; Griera, Tresor, XIV, pág. I24), toça 'cap del porc', 'nuca', etc. (Dicc. Aguiló; Griera, Tresor, XIV, pág. I 25 ); tozo Albacete, cast. tozuelo 'cerviz gruesa, carnosa de un animal'.

arag. tozar = topetar 'dar con la cabeza en alguna cosa con golpe e impulso, lo cual se dice con propiedad de los carneros y otros animales cornudos' (Dicc. Acad.); cat. retossar 'saltar els animais donant-se cops 
de cap' (Griera, Tresor, XII, pág. I68) ; valenc. toçoló 'golpe de cabeza contra una cosa dura'; cast. retozar 'saltar y brincar alegremente'.

Nótase claramente el sentido despectivo que se da al vocablo aplicado con preferencia a animales. Predomina la acepción de toza y sus derivados = 'cabeza, frente, testuz' en la zona catalana-aragonesa, encontrándose unos cuantos vestigios también en la zona castellana.

La misma delimitación geográfica se observa también en el caso siguiente:

cat. tossa 'pla alt del cim d'una muntanya', tossal, toçal 'la punta d'una muntanya', 'part alta del bosc, el turó' (Dicc. Aguiló; Griera, Tresor, XIV, pág. 1 25), vocablo frecuentísimo también en la toponimia catalana; arag. tozal 'monte, collado, lugar alto eminente' (BorAo; PARDo Asso).

No cabe duda que cat. tossa, empleado en sentido geográfico = 'parte alta de una montaña', se relaciona directamente con cat. tossa, arag. toza = 'parte alta de la cabeza, cabeza'. En cuanto a este último, García de Diego, RFE, XI, 1924, págs. $347-348$, se inclina a derivarlo de t o n s u s ('pelado' $>$ 'muchacho' $>$ 'cabeza calva'); pero contradicen, además de la fonética aragonesa, las variantes catalanas (no tomadas en considerción por el insigne romanista). Creo que debe relacionarse toza = 'cabeza, testuz' ( $\mathrm{y}$ asimismo cat. tossa = 'parte alta de la montaña') con arag. toza = 'toçón, trozo que queda a la raíz del tronco'. Tal hipótesis es tanto más probable cuanto que observamos una coincidencia geográfica completa entre los diferentes significados de la palabra.

Pero ¿cuál será la etimología de toza-tossa? ¿Habrá que relacionar el vocablo que tantas ramificaciones semánticas presenta en la zona catalana-aragonesa con touza, touça, toiça, propios de los dialectos occidentales? Desde el punto de vista fonético, las dificultades no parecen insuperables, admitiendo una base común * t a u t i a, o mejor dicho * t a u t t i a . En cuanto al contenido semántico, las discrepancias son evidentemente mayores. Destácase claramente la zona catalana-aragonesa de las demás por el sentido especial de 'cabeza, testuz' (generalmente empleado en sentido despectivo) y de 'parte alta de la montaña' que allí se ha dado a la voz tossa - toza (y sus derivados). Pero esa zona conserva también el significado 'tocón, trozo que queda a la raíz del tronco', que se parece más a la semántica occidental y que es inseparable además de toza empleado en el sentido de 'viga grande', 'dintel', acepción difundida en el centro y en el Oeste de España. Adviértase además que con esta acepción concuerdan también touzo, toiço, etc., usados en el Oeste de la Península con el significado de 'eje del molino', 'timón del carro', etc. Claro que no en todos estos casos se trata de la acepción primitiva de la palabra. Tanto más nos inclinamos a admitir una base común arraigada desde los tiempos más remotos en la Península y que habrá sido la de * t a u t tia, de que ya hablamos antes, vocablo que debe haber significado originariamente 'tronco, tallo, arbusto'. Sub- 
siste esta acepción primitiva todavía en los dialectos del Oeste, donde ha conservado una vitalidad sorprendente, y esporádicamente en otras partes, sobre todo en aragonés. Admitiendo tal base común, no resulta difícil comprender la filiación semántica que acabamos de esbozar y que presenta hoy día una variedad geográficamente bien delimitada.

Universidad Nacional de Cuyo,

FrITZ KRÜGER Mendoza, Argentina. 